\title{
Comparison of Surface Roughness of Two Restorative Materials after the Application of Topical Fluorides
}

INTRODUCTION: Surface roughness and microhardness are the two important properties which provide compressive strength as well as abrasion resistance to the restorative materials. On the other side topical fluorides provide the protective function with its anti-cariogenic properties. GIC as a restorative material fulfills both of the requirements.

AIM: The aim of this study is to evaluate the effect of topical fluoride application on surface roughness of various restorative materials.

MATERIALS AND METHODS: This study was done on 20 extracted teeth, Conventional Glass Ionomers (Fuji II) and Resin Modified Glass Ionomers (3M ESPE Vitremer) were used as restorative materials. Topical fluoride application i.e. with $2 \%$ sodium fluoride using Knutson's technique was done followed by storing in artificial saliva for 24 hours and then blot dried for testing of surface roughness.

RESULTS: Through this study it was observed that the no statistical difference was found between both of the restorative materials. (P>0.05).

CONCLUSION: In oral environment strength and life span of restorative material is one of the important criteria and roughened surface can clinically deteriorate these properties of restoration. So it's important for a dentist to consider all the factors while applying and restoring the tooth surface.

KEYWORDS: Preventive, Fluoride, Dental Caries, Restorative Material, Surface Roughness

\section{INTRODUCTION}

In dentistry various kind of restorative materials are used but ideally they should possess long-term durability in the oral environment. It comes from physical properties of restorative filling materials which are surface roughness and microhardness, which correlate well to compressive strength and abrasion resistance. ${ }^{1}$ Among several of restorative materials, glass ionomer cements are extensively used for various procedures because of their properties, such as esthetics, rechargeability, biocompatibility, ability to release fluoride, and chemical bonding to enamel and dentin. ${ }^{2}$ Despite of these useful properties they are having shorter working time with longer setting time, susceptibility to early moisture contamination, dessication after setting and brittleness. ${ }^{1}$ Ultimately it will affect the physical and esthetic properties. To get rid of these problems resin modified glass ionomers and Giomers were introduced along with capability of releasing specific amount of fluoride with an anti-cariogenic effect. $^{2}$

Though fluorides are having major role in preventive dentistry due to their anticariogenic action but they are having some adverse effects on various esthetic restorative materials. ${ }^{3}$ As many of the topical fluorides, such as, Acidulated phosphate fluoride, Sodium fluoride, and Stannous fluoride, causes alteration in their surface roughness and microhardness when applied to the restorative materials. It was proved by many of the studies that acidulated phosphate fluoride creates superficial erosion on the outmost surface of composite resin and glass-ionomer cement. ${ }^{2,4}$ This further creates a roughened surface and that leads to the increased plaque adhesion and at last the tooth and periodontium is disturbed by its harmful effects due to surface discoloration of the restoration and formation of secondary caries. Along with surface hardness, micro hardness is also decreased which causes erosion and degradation of the material as well as shorten the longevity. ${ }^{4,5}$ Hence an attempt has been made through the present study to evaluate the effect of topical fluoride application on surface roughness of various restorative materials.

\section{METHODOLOGY}

The present study was conducted in the Department of Conservative Dentistry and Endodontics at Bhojia Dental College, Baddi, 
India. A total of 20 extracted teeth were taken in the study and Conventional Glass Ionomers (Fuji II) and Resin Modified Glass Ionomers (3M ESPE Vitremer) was used as restorative materials. The procedure involved the fabrication of 20 specimens by filling them with the said restorative materials. To ensure the uniform shape and size, brass mould of $6.5 \mathrm{~mm}$ inner diameter and $2 \mathrm{~mm}$ thickness was used. Different restorative materials were mixed and placed in the brass mould and pressed between Mylar strips on each side which was supported by glass slabs. LED curing light was used for curing of light cure material for 40 seconds as per manufacturer's instructions. Afterwards specimen were divided into two groups i.e. Group I: 10 pellets of Fuji II and Group II: 10 pellets of resin-modified glass ionomer cement.

Then, every group was subjected to its respective topical fluoride application i.e. with $2 \%$ sodium fluoride using Knutson's technique. All the specimens were stored in artificial saliva for 24 hours prior to testing and blot dried for testing of initial surface roughness. Surface roughness was measured using Surface Roughness Tester. After this initial surface roughness recording, the specimens were subjected to their respective topical fluoride treatment i.e. Sodium fluoride for four minutes each. Then again all the specimens were blot- dried and re-evaluated for changes in surface roughness using surface roughness tester. The mean surface roughness was calculated and subjected to statistical analysis. The statistical analysis was done on SPSS version 22.0 and independent $\mathrm{T}$ test was used for intergroup comparisons.

\section{RESULTS}

The present in vitro study was conducted to evaluate and compare the effect of topical fluorides on the surface roughness of conventional Glass Ionomer Cement, Resin modified Glass Ionomer Cement with the help of Surface Roughness tester. Twenty pellets were made from two restorative materials which were divided into two groups: Group I (conventional Glass Ionomer Cement; Fuji II), Group II (Resin Modified Glass Ionomer Cement, Vitremer).

Table 1 shows surface roughness of the restorative materials before and after treatment with topical fluorides. In conventional GIC before the application of $\mathrm{NaF}$, the surface roughness was $0.781 \pm 0.412$ and after $\mathrm{NaF}$ application the roughness decreased to $0.585 \pm 0.231$. The mean difference was $0.196 \pm 0.041$ which is at nonsignificant level i.e. $\mathrm{p}=0.06$. Whereas in resin modified GIC, before the application of $\mathrm{NaF}$, the surface roughness was $0.581 \pm 0.321$ and after $\mathrm{NaF}$ application the roughness increased to $0.723 \pm$ 0.412. The mean difference was $-0.142 \pm 0.325$ which is at non-significant level i.e. $\mathrm{p}=0.06$.

Table 2 shows the comparison of the difference in the surface roughness between various materials using Sodium Fluoride. The distribution of mean difference in the surface roughness using $\mathrm{NaF}$ in Glass Ionomer Cement and Resin Modified Glass Ionomer Cement is $0.196 \pm 0.041$ and $-0.142 \pm 0.325$ respectively at non-significant level i.e $\mathrm{p}=0.08$.

\section{DISCUSSION}

In today's era of modern dentistry prevention of dental caries is an important aspect rather than treatment of carious lesion. It's been proved in many studies that fluorides are the powerful method of preventing the dental caries. ${ }^{6}$ Various kind of self-applied as well as professionally applied fluorides are available in the market such as fluoridated toothpastes, mouth washes and fluoride gels etc, with more effectiveness on controlling the decaying of tooth through inhibition of demineralization as well as promotion of remineralization process. ${ }^{3,6}$

Despite the availability of various preventive methods still dental caries is considered to be a public health problem due to its widespread nature. To cure the dental caries, various restorative materials are in use such as amalgam, composites etc.mIn addition to composites, glass ionomer cements are also in use like conventional glass ionomer cements, resin-modified glass ionomer cements, and newer additions like giomers. ${ }^{7,8}$

In the process of application of topical fluoride gels and solutions like sodium fluoride $(\mathrm{NaF})$, stannous fluoride $\left(\mathrm{SnF}_{2}\right)$, surface of cemented tooth may be significantly altered which may further cause some potential adverse effects on various esthetic restorative materials and this 
further effect the clinical durability of restorations. 3,9

In the present study, the surface roughness was measured with a mechanical surface hardness tester/ profilometer on two different types restorative materials. It was seen through this study that there was a decrease in surface roughness of glass ionomer cement and an increase in the surface roughness of resin modified glass ionomer cement after sodium fluoride application. The differences were non- significant in the case of glass ionomer cement and resin modified glass ionomer cement. Similar results were found in the study done by Setty J V et al in 2003, ${ }^{10}$ where increased surface roughness in conventional glass ionomer cement and a decreased surface roughness in resin modified glass ionomer cement was found. But Dionysopoulos P et al. in 2003 reported that there was only minimum effect on the surface integrity of glass ionomer cement when sodium fluoride gel was applied to the restorative surface. ${ }^{2}$

It was also observed in our study that the mean difference in surface roughness between glass ionomer cement and resin modified glass ionomer cement was statistically non-significant. But results of our study are in disagreement with study done by Setty J V et al (2003), ${ }^{10}$ where the observed mean difference of surface roughness between glass ionomer cement and resin modified glass ionomer cement after application of sodium fluoride was statistically significant.

\section{CONCLUSION}

In oral environment, the strength and life span of restorative material is one of the important criteria and roughened surface can clinically deteriorate these properties of restoration. So its important for a dentist to consider all the factors while applying fluoride and restoring the tooth surface. As there was no significant difference found in our work in the surface roughness of glass ionomer cement and resin-modified glass ionomer cement, these can presumably be chance findings. Henceforth, it can be concluded through this study that topical fluoride application has no as such deleterious effect on the restorative materials and can be used safely as a preventive agent for the prevention of dental caries because it been popularly known that prevention is better than cure.

\section{REFERENCES}

1. Botta AC, Mollica FB, Ribeiro CF, Araujo MAM, Nicolo RD, Balducci I. Influence of topical acidulated phosphate fluoride on surface roughness of human enamel and different restorative materials. Rev odonto ciệnc. 2010;25(1):83-7.

2. Dionysopoulos P, Gerasimou P, Tolidis K. The effect of home-use fluoride gels on glass-ionomer ,compomer and composite resin restorations .J Oral Rehabil 2003;30:683-9.

3. Mousavinasab M, Meyers I. Fluoride release and uptake by glass ionomer cements, compomers and giomers. Res J Biol Sci. 2009; 4(5): 609-16.

4. Gill NC, Pathak A. Comparative evaluation of the effect of topical fluorides on the microhardness of various restorative materials: An in vitro study. J Indian Soc Pedod Prev Dent 2010;28(3):193-9.

5. Kula K, Nelson S, Kula T, Thompson V. In vitro effect of acidulated phosphate fluoride gel on the surface of composites with different filler particles. J Prosthet Dent 1986; 56(2): 161-9.

6. Yazici AR, Tuncer D, Antonson S, Onen A, Kilinc E. Effects of delayed finishing/polishing on surface roughness, hardness and gloss of toothcoloured restorative materials. Eur J Dent 2010;4:50-6.

7. Jehad RH. Comparison of the effect of stannous fluoride and sodium fluoride on surface roughness of silorane and methacrylate based restorative material using light polarizing microscope. J Bagh Coll Dent2011; 23(2):31-6.

8. Ismail SA. Evaluation of surface roughness of composite according to surface treatment. AlRafidain Dent J 2005;5(2):174-9.

9. Benderli Y, Gokce K, Kazak M. Effect of APF gel on micromorphology of resin modified glassionomer cements and flowable compomers. J Oral Rehabil 2005;32:669-75.

10. Setty JV, Singh S, Subba Reddy VV. Comparison of the effect of topical fluorides on the commercially available conventional glass ionomers, resin modified glass ionomers and polyacid modified composite resins- An in vitro study. J Indian Soc Pedod Prev Dent 2003;21(2):5569. 
Source of support: Nil, Conflict of interest: None declared

Cite this article as:

Khosla S, Verma V, Markan S. Comparison of Surface Roughness of Two Restorative Materials after the Application of Topical Fluorides. Int Healthcare Res J 2018;1(11):339-342.

\section{$\underline{\text { AUTHOR AFFILIATIONS }}$}

1. MDS (Periodontics and Implantology), Verma Multispecialty Dental Clinic, Jagraon

2. MDS (Prosthodontics including Crown, Bridge and Implantology), Verma Dental Multispecialty Clinic , Jagraon

3. Senior Lecturer, Department of Conservative Dentistry and Endodontics, Bhojia Dental College, Baddi

\section{Corresponding Author:}

\section{Dr. Saru Khosla}

MDS (Periodontics and Implantology)

Verma Multispecialty Dental Clinic

Jagraon

For manuscript enquiry/author contact details, e-mail at:

maunscriptenquiry.ihrj@gmail.com

\section{LEGENDS}

\begin{tabular}{|c|c|c|c|c|c|}
\hline TYPE OF GIC & $\begin{array}{c}\text { BEFORE } \\
\text { APPLICATION }\end{array}$ & $\begin{array}{c}\text { AFTER } \\
\text { APPLICATION }\end{array}$ & DIFFERENCE & P VALUE & SIGNIFICANCE \\
\hline $\begin{array}{c}\text { CONVENTIONAL } \\
\text { GIC }\end{array}$ & $0.781 \pm 0.412$ & $0.585 \pm 0.231$ & $0.196 \pm 0.041$ & 0.06 & Non-significant \\
\hline $\begin{array}{c}\text { RESIN MODIFIED } \\
\text { GIC }\end{array}$ & $0.581 \pm 0.321$ & $0.723 \pm 0.412$ & $-0.142 \pm 0.325$ & 0.06 & Non-significant \\
\hline
\end{tabular}

Table 1. Surface roughness (in $\mu \mathrm{m}$ ) of restorative materials before and after treatment with topical fluorides

\begin{tabular}{|c|c|c|c|}
\hline Type of GIC & $\begin{array}{c}\text { Mean } \\
\text { Difference }\end{array}$ & P value & Significance \\
\hline $\begin{array}{c}\text { Conventional } \\
\text { GIC }\end{array}$ & $0.196 \pm 0.041$ & \multirow[t]{2}{*}{0.08} & \multirow{2}{*}{$\begin{array}{c}\text { Non- } \\
\text { significant }\end{array}$} \\
\hline $\begin{array}{c}\text { Resin Modified } \\
\text { GIC }\end{array}$ & $-0.142 \pm 0.325$ & & \\
\hline
\end{tabular}

Table 2. Mean difference comparison of surface roughness between various materials 